\title{
Climate Change Movements and Psycho-Social Disorder
}

\section{Introduction}

This paper presents a sketch of the problems involved in social movements responding to climate change, coming to produce new modes of action and representation. Understanding the richness and confusion of these responses, and the ways movements can arise from disorder while producing self-undermining disorder, requires a) anthropology, b) a relatively explicit psychology and c) an awareness that 'disorder' is not a residue or pathology, but both a driver and potentially creative factor in events.

'Disorder' is that which escapes or disrupts the socially available ordering process; so what counts as 'disorder' varies with the social and political position of those making the evaluation. Disordering and rubbish-making, tell us as much about social process as modes of ordering do. Climate change, for example, not only disorders the psychosocial complex of a society, but the ways the problem is ordered, represented and acted upon, may also disrupt that society's attempts at a constructive response.

For me, the bridging term between psyche and social is 'imagination', as approached through David Hume (1711-1776) and Carl Jung (1875-1961); partly because they are among the few western writers who take disorder seriously. Hume (1888) argues that humans are driven by imagination and passion not primarily reason. The sense of patterning we have in the world is provided by social relations (through empathy, rivalry, hostility and habit) and through the linking activities of imagination. The 'ego', or sense of self, is made up of habitual linkages, and the perceptions these linkages select. We imagine through sensory analogues, so mentation is embodied. Jung suggests both that 'psyche' is entranced in image and is creative and selfcorrective. He proposes we have a shared unconscious dynamics, which is partially social and crystallises in common 'mythic' patterns that are reinforced by, or compensatory to, conscious worldviews. For Jung, ego consciousness always disrupts the wider 'ecological' dynamics of the Self, and is therefore always under the threat of transformation (see Marshall 2009: xi ff.,197ff). 
Social power depends upon an imagining of rightness and the anticipation of consequences. Although power may ultimately require violence, use of violence risks disturbing power relations, and so is often deferred. Power can be traced by easily triggered, habitual, social and imaginal pathways, and by the 'magic' of rhetoric and myth that pictures the consequences of action, but which also allows challenge to the legitimacy and order of those power relations.

\section{Climate Change and Disruption}

Climate movements are motivated by imaginings of the future, are grouped by shared imaginings and by imagining themselves as joined. They work against imagined groups of others (who they rarely encounter directly as groups), and they imagine the consequences of their actions. This is not to say that all consequences are equally probable, but that the future does not currently exist. These imaginings of the future, and of others, are affected by whatever orders and disorders social imagination.

Due to this constant imagining, climate change is a psychological fact as much as a social and physical fact. It is messy and disruptive; socially, economically, and conceptually. By implying that the world cannot continue, whether you deny, accept, or take any place between, it disrupts ego-habits and opens us up to the unconscious, whether personal or collective. The configuration of challenges which society has adapted to is disrupted, and established solutions become problematic. Climate change breaks customary linkages, habits and patterns. Bion (1967) suggests that such fragmentation of perception and organisation can lead to psychosis. Jung suggests it can also lead to new life.

The largely unpublished work of James Goodman and Rebecca Pearse (see Pearse et al 2010), show that climate change activists often go through a stage of being torn by their vulnerabilities and internal psychological oppositions. They face what they often see as the impossibility of stopping climate change, but sense the necessity to try. Imagining the future can be paralysing. People talk of taking to their beds for weeks, in depression or tears; of overwhelming anger; of oscillating between hopelessness and determination, of the life changing experience of feeling that something has to be done, whatever its folly. 
The paths they described were unruly, both in the telling, and undoubtedly in the experience. Narratives enlisted by participants were internally dynamic, both gradual and punctuated by transformatory moments, linear and disjointed... Expressions of awakening or moral shocks figure in participant's stories to explain shifts in thinking, feeling and occasionally a new life trajectory (ibid: 90).

Similarly, when editing a collection of essays on climate change (Marshall 2009), I was struck by the fragmentation of argument, the halts and hesitations, and by peoples' desire to list evil. Although contributors had been asked not to write about the 'facts' of climate change, many compulsively listed those facts even when irrelevant to their paper. I myself could not stop writing. Perhaps, listing is a defence that restores ritual order, providing stability and habit amongst disorder? We can see similar disruptions in the 'denial movement'. Activist 'sceptics' display anger and disorientation, often positing vast, powerful conspiracies of scientists and left-wing activists to explain their sense of disruption. They often display too many contradictory reasons for not acting, and they compulsively list 'facts' which have been disproved, while accusing others of ignoring the data.

Through our imagining, the situation's complexities are reduced to a binary, each caught in its own rhetoric and passion. What Jungians call 'the shadow', the disowned parts of our own being, are projected onto the others who then become evil and disruptive to us. The ordering binary of good and evil, is reiterated even as those binaries break down. At Copenhagen, the binary of industrialised vs. developing nations, or North vs. South, crumbled into fragmentary, temporary and shifting alliances that satisfied no one and confused all; but, nevertheless, many people still reported the events in terms of old binaries.

Fundamentally, climate change is big, so big that we cannot, as yet, conceptualise it (however much we list); and so it becomes symbolic, invoking existential issues about the meanings of life, death, distribution of suffering, relation of humans to the cosmos and so on. We imagine and feel with its images; floods, deserts, storm and drought are already parts of our psyche and our dreams. Hence the imagined disruption of climate change is much more a focus for social interest than other ecological catastrophes, and it takes on the mythic templates with which we have previously handled such existential problems. 


\section{Myth}

Myth is a culturally available narrative, which in Jungian theory serves both social and individual functions. It organises thoughts and actions, acts as a mode of indoctrination, and provides guides to development within, and sometimes outside, accepted social frameworks. Myth may not always be adequate to the configuration of challenges that people face, especially in times of disruption. Yet there is always the capability of producing new myths, or reinterpreting old ones, due to the creative potential of the unconscious compensating for restrictive ego habits, through the upwelling of image, pattern and linkage. This upwelling, however, can result in 'paranoid totalisation', in which the linkage of ideas always returns to a particular focus. This produces disruption through psychological over-organisation. There is no guaranteed path.

Some common myths found ordering Western climate movements and responses include 'Eden’, ‘Apocalypse’ and 'Justice’ (Hulme 2009). Myths frequently contradict one another, thus potentially invoking an immobilising rhetoric.

The Myth of Eden tells of the loss of something pristine and naturally ordered. It is the foundational myth of 'wilderness', and often invoked when we are shown an area with life but no humans. Often the absence of humans occurs because the Eden is artificial and walled. The myth also holds a counter-position, a diametric opposite, as nature can be perceived as brute, hostile and opposed to humans. Eden links loss, desire and fear; the fear propelling us to impose order on the world, with an equal awareness that imposing this order can be destructive. Within it, we are caught in unresolved mythic opposites.

In the Western myth of Apocalypse, the end of the world is nigh and out of our hands, and the good survive anyway. There is nothing we can do; it is the will of God. The myth may prod us into action but it is an essentially passive action. Perhaps we call for repentance, a change of life, for purity, or the obliteration of others, to become worthy of being saved. We must prepare for the end, and this probably produces despair, as no actions can be enough. Its counter-position is that within the destruction a radical change of consciousness may occur, heralding the millennium in 
which all problems are solved magically. Destruction can be welcomed, as the coming collapse, and the death of billions of people foreshadow the return to Eden. Attempts at solutions such as engaging with renewable energy, become a way of wasting time on our way to the end. This purity melds with claims by climate change deniers that efforts to change society express the sin of economic disruption and socialism.

Another central myth of climate action is 'Climate Justice'. This easily becomes a way of asserting moral superiority and projecting shadows as justice holds a binary within it; people are innocent or guilty. However, people have different notions of justice and resist being defined as criminal, so there is little room for negotiation. India and China can argue that Justice is served if they can pollute now, as 'the West' has done previously; to deny them is unjust imperialism. By being absolute, Justice ignores the conflict of different ways of life. Applying Justice requires a centralised and global hierarchy of violence and compulsion to enforce decisions; which is probably not the aim of the 'climate justice movement'. Neither Apocalypse nor Justice gives a useful re-imagining of power relations and conflict.

It is hard to say what new myths are emerging; research is required. Myths of 'interconnectivity' seem to be gaining currency, but frequently these are phrased in Edenic terms, as if humans are cut off from the world, or have lost their connectivity, or need to be forced into it. Interconnectivity can even be used to reduce the world to the economy. The movements have not yet crystallised new imaginal directions, or symbologies to guide their energies and put them in a less precarious position.

\section{Conclusion}

The world is disordered by our mode of ordering, and this is expressed in the inner and outer life of climate change and climate change movements. Understanding this process helps us to understand the contradictions and possibilities of climate movements. Myths order and disorder our imaginings of power relations and our anticipations of the future, especially when we are disoriented. They both imply a position and a counter-position. In Jungian theory if we contemplate, and fully entertain, these incompatibilities, while attempting to withdraw our shadow projections from others, then new bridging symbols will be generated and new myths 
emerge. This is the hope. Bearing in mind the dangers of totalising paranoia, we can test these myths, introduce them to others, and see if they open the ways we live, organise, and relate to disorder. This could be a practice.

\section{References}

Bion, Wilfred. 1967. Second Thoughts. London: William Heinmann.

Hulme, Mike. 2009. Why We Disagree About Climate Change: Understanding Controversy, Inaction and Opportunity. Cambridge University Press.

Hume, David. 1888. Treatise of Human Nature. Oxford University Press.

Marshall, J.P. 2009. Depth Psychology, Disorder and Climate Change. Sydney: JungDownunder Books.

Pearse, R., Goodman, J. \& Rosewarne, S. 2010. Researching Direct Action Against Carbon Emissions: A Digital Ethnography of Climate Agency. Cosmopolitan Civil Societies Journal, 2(3): 76-103. 
This is the peer reviewed version of the following article: Marshall Jonathan 2011, 'Climate change movements and psycho-social disorder', Wiley, vol. 22, no. 2, pp. 265-269. which has been published in final form at http://dx.doi.org/10.1111/j.1757-6547.2011.00131.x This article may be used for non-commercial purposes in accordance With Wiley Terms and Conditions for self-archiving' 